\title{
Comparison of Frictional Coefficient and Surface Roughness between Three Different Active Self-ligating Brackets: An Experimental In Vitro Study
}

\author{
Meralda R. Syahdinda, Lucky Lucynda, Ari Triwardhani, Thalca Hamid \\ Department of Orthodontic, Faculty of Dental Medicine, Universitas Airlangga, Surabaya, Indonesia
}

\section{AвSTRACt}

Aim: In orthodontic treatment, the high levels of friction may reduce the effectiveness of the mechanical and decrease tooth movement efficiency. The use of active self-ligating brackets is claimed to possibly reduce friction in orthodontic treatment. The aim of this study was to investigate the three-different active self-ligating orthodontic brackets in frictional coefficient and surface roughness. Materials and Methods: This study was true-experiment laboratory with posttest group design to collect the frictional coefficients data from three different active self-ligating brackets. Friction tests were performed on three different active self-ligating brackets-In-Ovation R, Empower, and BioQuick. Each group consists of seven samples of active self-ligating brackets-and stainless steel wire which has been stored in artificial saliva solutions for 14 days. After the friction coefficients of every sample obtained, the bracket clips were separated from the bodies and set on resin acrylic medias. Surface roughness of the bracket clips was evaluated using the atomic force microscope (AFM). A one-way analysis of variance (ANOVA) followed by Scheffe test for comparisons was performed statistically $(P<0.05)$. Results: BioQuick and Empower orthodontic brackets produced lower frictional coefficients compared to In-Oviation-R brackets. BioQuick showed least frictional coefficients. Based on the statistical analysis, there was no significant difference of frictional coefficients between Empower and BioQuick. Surface roughness test showed that the clip surface of In-Ovation R produced the maximum roughness, followed by Empower and BioQuick. Conclusion: In-Ovation R brackets offered more frictional coefficients and surface roughness than Empower and BioQuick brackets, whereas BioQuick brackets offered the least among all the brackets studied.

Keywords: Active Self-Ligating Bracket, Friction Coefficient, Surface Roughness

Received: 13-02-2020, Revised: 12-04-2020, Accepted: 08-05-2020, Published: 30-11-2020.

\section{INTRODUCTION}

Orthodontic treatment using fixed appliances is based on the specific forces that is applied to the teeth through the attachment of brackets. ${ }^{[1]}$ Extreme friction forces will impede the teeth movement and detract the efficacy of the appliances. ${ }^{[2]}$ Friction is affected by biological factor - such as saliva, debris, and biodegradation of the appliance's components that has been used - and physical factor as the using of brackets, archwires, and ligations. ${ }^{[3]}$ The shape, size, and structures of the fixed appliances' components will affect the treatment result. ${ }^{[4]}$

The generated forces of bracket and archwire interactions can be measured from its surface roughness. Surface

\begin{tabular}{|l|l|}
\hline \multicolumn{2}{|c|}{ Access this article online } \\
\hline Quick Response Code: & Website: \\
\hline & www.jioh.org \\
\cline { 2 - 2 } & \\
\hline
\end{tabular}

roughness is texture of a superficial area that gives impacts to the object against its environment. ${ }^{[5]}$ Increased surface roughness can increase frictional forces because it enhances the contact area between the bracket and the archwire. ${ }^{[6]}$

Along with the development in orthodontics, many experiments have been done in order to decrease the friction between bracket and archwire, particularly in sliding mechanics such as the invention of orthodontic

Address for correspondence: Dr. Ari Triwardhani, Department of Orthodontic, Faculty of Dental Medicine, Universitas Airlangga, Jl Mayjen Prof. Dr. Moestopo 47, Surabaya, Indonesia. E-mail: ari-t@fkg.unair.ac.id

This is an open access journal, and articles are distributed under the terms of the Creative Commons Attribution-NonCommercial-ShareAlike 4.0 License, which allows others to remix, tweak, and build upon the work non-commercially, as long as appropriate credit is given and the new creations are licensed under the identical terms.

For reprints contact: reprints@medknow.com

How to cite this article: Syahdinda MR, Lucynda L, Triwardhani A, Hamid T. Comparison of frictional coefficient and surface roughness between three different active self-ligating brackets: An experimental in vitro study. J Int Oral Health 2020;12:551-5. 
self-ligating bracket. $^{[7]}$ The mechanism of self-ligating brackets helps teeth to move freely into the normal positions due to the low friction. ${ }^{[8]}$

Therefore, the purpose of this research was to investigate the three-different active self-ligating orthodontic brackets in frictional coefficient and surface roughness.

\section{Materials and Methods}

\section{Study design}

This study was true-experiment laboratory with posttest group design to collect the frictional coefficients data from three different active self-ligating brackets of \#14 premolar. Friction tests were performed on three different active self-ligating brackets - In-Ovation R (GAC-Dentsply, USA), Group II of Empower (American Orthodontics, Sheboygan, Wisconsin, United State), and Group III of BioQuick (Forestaden, Pforzheim, Germany). The three-different orthodontic self-ligating brackets were examined by means of $016 \times$ 0.022 inches rectangular stainless steel archwire (American Orthodontics, Sheboygan, Wisconsin, United State).

\section{Sample preparation}

Samples were divided into three groups of brackets and a group of archwire. Each group of brackets consists of seven samples, whereas the archwire group consists of four archwires which each has been cut into half to get eight pieces in total. Each group was soaked in $6.5 \mathrm{pH}$ of artificial saliva solution in a glass petri dish. All the four petri dishes then wrapped and stored in $37^{\circ} \mathrm{C}$ incubators for 14 days. Medias to place the brackets were made from 1.3-cm-diameter resin acrylic with iron nail attached as the hook [Figure 1A]. Brackets were fixated using cyanoacrylate adhesive.

\section{Friction and topography test}

Brackets and archwires which had been stored in artificial saliva solution were tested using Universal Testing Machine (AG 500 E, Shimadzu Autograph Japan) [Figure 1B]. Archwires were fixated into the brackets by locking the brackets' slot clips. The nail attached in the resin acrylic media would be hooked into the Universal Testing Machine. The friction tests were done on each sample, in $27^{\circ} \mathrm{C}$ room temperature and dry environment.

As much as $2 \mathrm{~N}$ (newton) force was applied to every orthodontic archwire. A total of 21 results were documented (three types of bracket $\times$ seven sample). After the friction coefficient details of every sample obtained, the outer part of the bracket clips was marked and separated from the bodies using disc diamond bur. After that, the parts which have already been marked would set on other resin acrylic medias, so that the inner part of the clip would face upward. Surface roughness of the bracket clips was evaluated using atomic force microscope (AFM) (Bruker) to obtain the numbers of surface deviation and to evaluate its topography structure [Figure 1C].
AFM has a cantilever and a probe that work as detector which would scan the clip surface in 10 micron areas. From the tests, quantitative data $(\mathrm{Sa}=$ average roughness) and qualitative data (2D and 3D picture) were obtained.

\section{Statistical analysis}

Analysis of variance was done to examine the difference between groups continued by Scheffe test $(P<0.05)$ or Kruskal-Wallis was done to compare the difference continued by Wilcoxon Mann-Whitney $(P<0.05)$ based on the result of Levene test and Shapiro-Wilk statistical analysis $(P>0.05)$.

\section{Results \\ Frictional test}

In-Ovation $\mathrm{R}$ brackets produced higher frictional coefficients than Empower and BioQuick. BioQuick showed least frictional coefficients. Based on the statistical analysis, there was no significant difference of frictional coefficients between Empower and BioQuick.

Table 1 shows the descriptive statistics of the frictional forces for active self-ligating brackets. There was significant difference in coefficient frictional between groups were $(P<0.05)$. Scheffe test that presented in Table 2 showed significant mean frictional value differences between In-Ovation $\mathrm{R}$ and BioQuick brackets, as well as In-Ovation $\mathrm{R}$ and Empower $(P<0.05)$. Meanwhile, Empower and BioQuick showed no frictional coefficient differences.

\section{Surface roughness test}

The quantitative data from the surface roughness tests that had been collected show that the bracket clip surface of In-Ovation $\mathrm{R}$ produced the maximum roughness, followed by Empower and BioQuick. The Kruskal-Wallis test was used to compare the average between groups continued by Mann-Whitney test to compare the average of each group.

Table 3 shows significant differences of surface roughness among the three experimental bracket groups. The qualitative data showed the same outcome as the statistic results as seen in Figures 2 and 3.

As seen in Figure 2A, the surface of In-Ovation R clip was dominated by dark brown to black areas, whereas in Figure 2B the surface of Empower clip has less dark areas compared to In-Ovation R clip. The surface of BioQuickclip as seen in Figure $2 \mathrm{C}$ was more stable with more yellow areas dominated.

Figure 3A shows the surface of In-Ovation clip. It shows an uneven surface, with mostly jagged areas. In the middle area, there is a depression which is shown by deep brown color. Figure 3B shows the surface roughness of Empower clip, which is dominated by hollows-like areas. Figure 3C shows BioQuick clip's surface. The surface seems more even compared to In-Ovation and Empower surfaces. The $2 \mathrm{D}$ and $3 \mathrm{D}$ images from AFM showed that In-Ovation R bracket clip has the highest surface roughness, followed by Empower and BioQuick. 
Syahdinda, et al:: Comparison of frictional coefficient and surface roughness

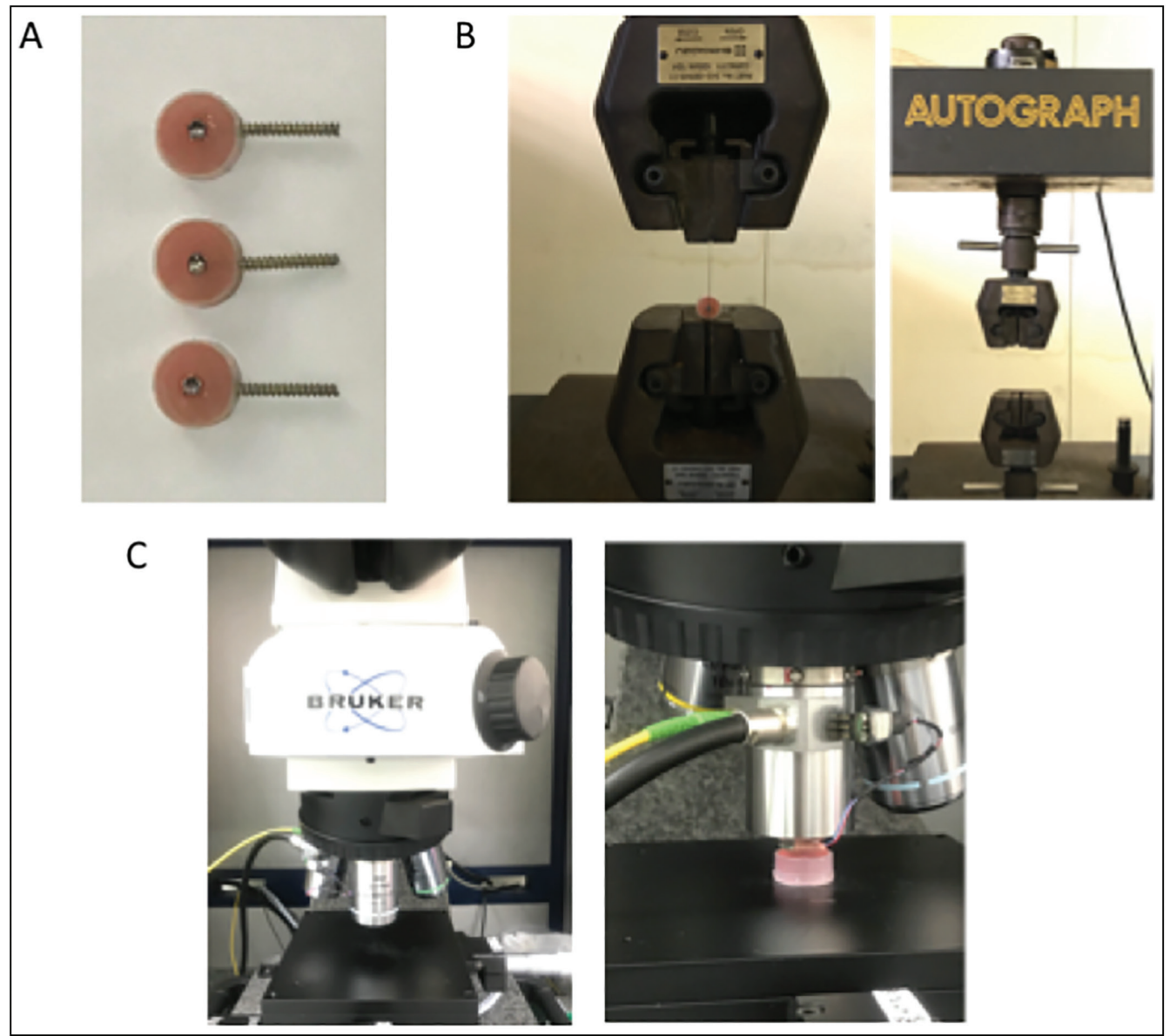

Figure 1: (A) Resin acrylic media for bracket placement. (B) Frictional test using Universal Testing Machine. (C) Surface roughness test using atomic force microscope

\begin{tabular}{|c|c|c|c|c|}
\hline \multicolumn{5}{|c|}{$\begin{array}{l}\text { Table 1: One-way analysis of variance comparing frictional } \\
\text { coefficients in Newton }\end{array}$} \\
\hline Bracket & Mean & SD & $F$ Value & $P$ Value \\
\hline & & & 79.947 & $0.001^{*}$ \\
\hline In-Ovation & 0.041 & 0.006 & & \\
\hline Empower & 0.016 & 0.004 & & \\
\hline BioQuick & 0.011 & 0.002 & & \\
\hline
\end{tabular}

$\mathrm{SD}=$ standard deviation

*Significant at $P<0.05$

\section{Discussion}

According to the previous studies, the teeth movement in sliding mechanics is not a sustainable gliding motions, but series of a very smooth tipping and uprighting motions. During the process of sliding mechanics, the forces that applied to the teeth would cause tipping and rotation. ${ }^{[9]}$ When the teeth rotate, arch wire will make a contact with the distal edge of the buccal clip/spring clip. The material of the bracket clip would affect the friction value. Material of brackets that produce the highest friction force is $\beta$-titanium, followed by nickel-titanium (Ni-Ti), cobalt-chromium ( $\mathrm{Co}-$ $\mathrm{Cr}$ ), and stainless steel. ${ }^{[10]}$ Empower and BioQuick clips were made of stainless steel, whereas In-Ovation R clip material were $\mathrm{Co}-\mathrm{Cr}^{[11]}$ Active clip from self-ligating brackets are made of various type of metals with different characteristic and rigidity. The more rigid (or less compressible) the clip material, the higher the friction force produced. ${ }^{[12]}$ This theory supports the results of this study that is the bracket clip of In-Ovation R, which has $\mathrm{Co}-\mathrm{Cr}$ material, produced higher friction coefficient than Empower and BioQuick, which have stainless steel as their main material.

In-Ovation R, Empower and BioQuick brackets have spring clips that transfer active forces from archwire to the bracket slot. The ligation mechanism of Empower bracket required its stainless-steel clip to be pulled down to fix the bracket aperture and archwire. The interactive clip is flexible and move in circular motion along with the archwire. ${ }^{[13]}$ In-Ovation $\mathrm{R}$ bracket has agile buckle system which pass by occlusogingival to the edgewise slot. It is a full slot clip coverage that allows interaction between the clip and archwire. In-Ovation R's clip is more rigid than Empower's. ${ }^{[2]}$ BioQuick bracket has rounded slot edges and contact ribs which can produce minimal friction. ${ }^{[14]}$

Aside from its self-ligating mechanism, the main cause of the frictional coefficient differences produced is the geometric design of the brackets. Wider surface brackets 
Syahdinda, et al.: Comparison of frictional coefficient and surface roughness

\begin{tabular}{|c|c|c|c|c|c|c|c|}
\hline & \multirow[t]{2}{*}{ (I) } & \multirow[t]{2}{*}{ (J) } & \multirow{2}{*}{$\begin{array}{c}\text { Mean difference } \\
(\mathrm{I}-\mathrm{J})\end{array}$} & \multirow[t]{2}{*}{ Std. error } & \multirow[t]{2}{*}{ Sig. } & \multicolumn{2}{|c|}{ 95\% Confidence interval } \\
\hline & & & & & & Lower bound & Upper bound \\
\hline \multirow{6}{*}{ Scheffe } & In-Ovation & BioQuick & 0.030000 & 0.002542 & $0.001^{*}$ & 0.02322 & 0.03678 \\
\hline & $\mathrm{R}$ & Empower & 0.025000 & 0.002542 & $0.001 *$ & 0.01822 & 0.03178 \\
\hline & BioQuick & In-Ovation $\mathrm{R}$ & -0.030000 & 0.002542 & $0.001 *$ & -0.03678 & -0.02322 \\
\hline & & Empower & -0.005000 & 0.002542 & 0.173 & -0.01178 & 0.00178 \\
\hline & Empower & In-Ovation $\mathrm{R}$ & -0.025000 & 0.002542 & $0.001^{*}$ & -0.03178 & -0.01822 \\
\hline & & BioQuick & 0.005000 & 0.002542 & 0.173 & -0.00178 & 0.01178 \\
\hline
\end{tabular}

*Significant at $P<0.05$

\begin{tabular}{lccc}
\hline \multicolumn{4}{l}{ Table 3: Comparison of surface roughness among the three experimental bracket groups } \\
\hline Parameters & In-Ovation $(\boldsymbol{N}=\mathbf{7})$ & Empower $(\boldsymbol{N}=7)$ & BioQuick $(\boldsymbol{N}=7)$ \\
\hline Range & $9.40-11.00$ & $16.40-20.00$ & $15.80-33.00$ \\
Mean \pm std. error & $10.29 \pm 0.22^{\mathrm{a}, \mathrm{b}}$ & $18.23 \pm 0.45^{\mathrm{a}, \mathrm{c}}$ & $25.94 \pm 2.15^{\mathrm{b}, \mathrm{c}}$ \\
Median & 10.60 & 18.20 & 27.60 \\
Std. deviation & 0.59 & 1.19 & 5.68 \\
\hline
\end{tabular}

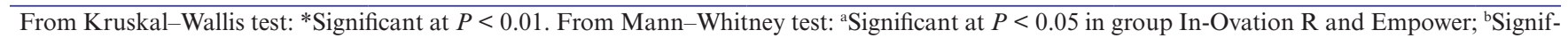
icant at $P<0.05$ in group In-Ovation $\mathrm{R}$ and BioQuick; 'Significant at $P<0.05$ in group Empower and BioQuick

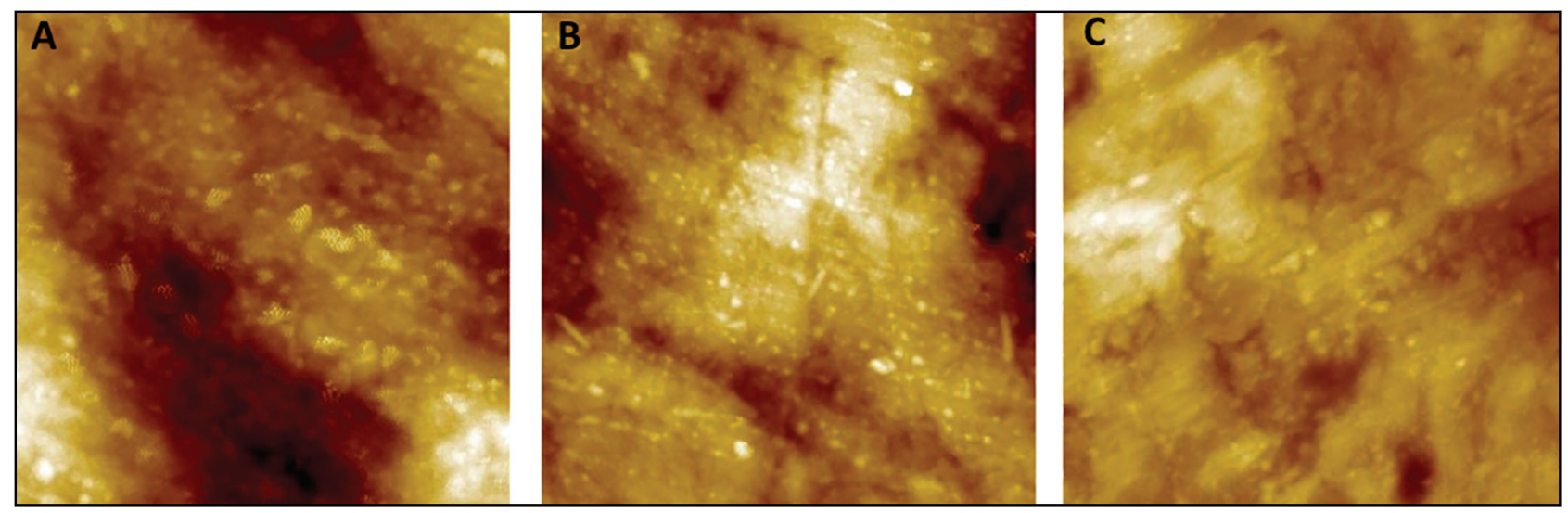

Figure 2: 2D surface images of clip brackets: (A) In-Ovation R, (B) empower, and (C) BioQuick using atomic force microscope
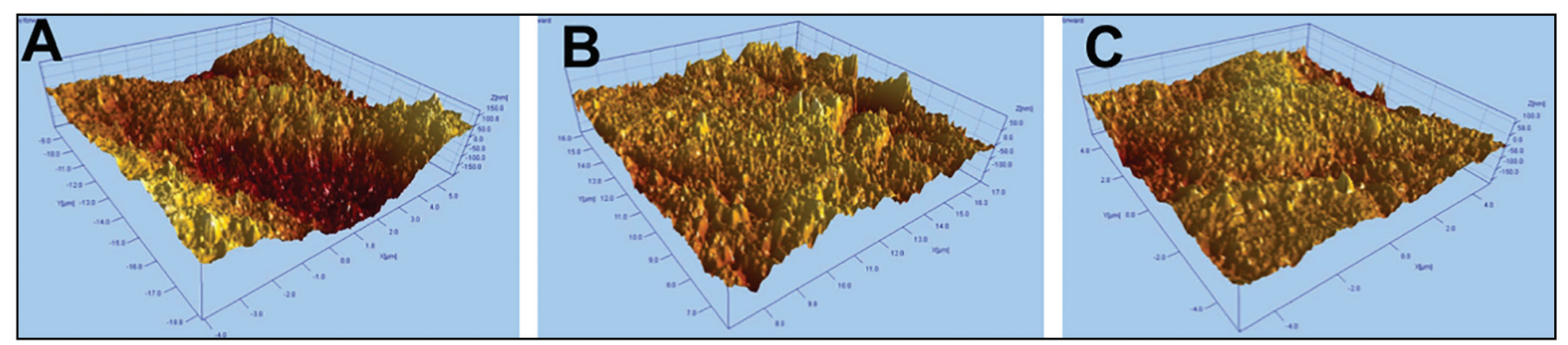

Figure 3: 3D surface images of clip brackets: $(A)$ In-Ovation $R$, $(B)$ empower, and $(C)$ BioQuick using atomic force microscope

will provide lower friction than the narrow ones because archwires can move more freely. ${ }^{[15]}$ From the previous studies, BioQuick bracket has the widest slot dimension than Empower and In-Ovation R, which is $3,000 \mathrm{~mm}$. It supports this study result that BioQuick produced lowest frictional coefficient between the three brackets. Slot of Empower is a little narrower in dimension than BioQuick, $2946 \mathrm{~mm}$, whereas for In-Ovation R is $2667 \mathrm{~mm} \cdot{ }^{[16]}$ It goes along with this study result that showed In-Ovation $\mathrm{R}$ bracket has the highest frictional coefficient.

The result of surface roughness tests in this study is incongruent with the frictional tests result. The previous studies showed that the surface roughness of a material relates to its frictional coefficient. ${ }^{[17]}$ Surface roughness of the brackets can be affected by its surface 
structures, such as material, coating, manufacture techniques, and the interaction between bracket and archwire. ${ }^{[18]}$

\section{Conclusion}

In-Ovation $\mathrm{R}$ brackets offered more frictional coefficients and surface roughness than Empower and BioQuick brackets, whereas BioQuick brackets offered the least among all the brackets studied.

\section{Acknowledgement}

The authors wish to thank Faculty of Pharmacy, Universitas Airlangga and Faculty of Material and Metallurgy, Institute Technology Sepuluh Nopember for providing support in the conduct of this study and also the staff of the departments for their generous assistance in carrying out the experiments.

\section{Source of Funding}

Self-funding (nil).

\section{Conflict of Interest}

There is no conflict of interest in this study.

\section{Author contributions}

Conceptualization, Methodology, Investigation, Formal Analysis, Supervisor project: AT, TH; Writing - Original Draft Preparation, Writing - Review and Editing, Project Administration and Funding Acquisition: MRS, LL.

\section{Ethical policy and Institutional Review board statement}

This study was in vitro study, the ethical policy or ethical clearance certificate is not needed.

\section{Data Availability statement}

The availability is available on request to author (ari-t@ fkg.unair.ac.id).

\section{List of Abbreviations}

AFM: atomic force microscope, NiTi: nickel-titanium, Co-Cr: cobalt-chromium.

\section{RefERENCES}

1. Almosa N, Zafar H. Incidence of orthodontic brackets detachment during orthodontic treatment: A systematic review. Pak J Med Sci 2018;34:744-50.
2. Prashant PS, Nandan H, Gopalakrishnan M. Friction in orthodontics. J Pharm Bioallied Sci 2015;7:S334-8.

3. Almeida FA, Almeida AP, Amaral FL, Basting RT, Franca FM, Turssi CP. Lubricating conditions: Effects on friction between orthodontic brackets and archwires with different cross-sections. Dental Press J Orthod 2019;24:66-72.

4. Papageorgiou SN, Keilig L, Hasan I, Jager A, Bourauel C. Effect of material variation on the biomechanical behaviour of orthodontic fixed appliances: A finite element analysis. Eur J Orthod 2016;38:300-7.

5. Rudge $\mathrm{P}$, Sherriff $\mathrm{M}$, Bister DA, Comparison of roughness parameters and friction coefficients of aesthetic archwires. Eur J Orthod 2015;37:49-55.

6. Usui T, Iwata T, Miyake S, Otsuka T, Koizumi S, Shirakawa N, et al. Mechanical and frictional properties of aesthetic orthodontic wires obtained by hard chrome carbide plating. J Dent Sci 2018;13:151-9.

7. Faizee KM, Thomas S, Khrisnaswamy NR. Frictional characteristics of active and passive self-ligation bracket systems: An in vitro Study. J Indian Orthod Soc 2011;45:154-9.

8. Jangde A, Garg A, Virang B, Sahu S. Self ligating brackets from past to presnt: An update. IOSR J Dent Med Sci 2018;17:30-43.

9. Ribeiro GL, Jacob HB. Understanding the basic of space closure in orthodontic for a more efficient orthodontic treatment. Dent Press J Orthod 2016;21:115-25.

10. Kumar D, Dua V, Mangla R, Solanki R, Solanki M, Sharma R. Frictional force released during sliding mechanics in nonconventional elastomerics and self-ligation: An in vitro comparative study. Indian J Dent 2016;7:60-5.

11. Franco EM, Valarelli FP, Fernandes JB, Cancado RH, Freitas KM. Comparative study of torque expression among active and passive self-ligating and conventional brackets. Dental Press J Orthod 2015;20:68-74.

12. Gómez-Gómez S-L, Villarraga-Ossa J-A, Diosa-Peña J-G, OrtizRestrepo J-F, Castrillón-Marín R-A, Ardila, CM, et al. Comparison of frictional resistance between passive self-ligating brackets and slide-type low-friction ligature brackets during the alignment and leveling stage. J Clin Exp Dent 2019;11:e593-600.

13. Francisconi MF, Janson G, Henriques JF, Freitas KM, Francisconi PA. Evaluation of the force generated by gradual deflection of 0.016-inch niti and stainless steel orthodontic wires in self-ligating metallic and esthetic brackets. J Clin Exp Dent 2019;11:e464-9.

14. Cappellette M. In vitro comparison of friction generated by various models of self-ligating and conventional brackets while performing retraction with sliding mechanics. Global J Med Res J Dent Otolaryngol 2017;17:1.

15. Lee SM, Hwang CJ. A comparative study of frictional force in selfligating brackets according to the bracket-archwire angulation, bracket material, and wire type. Korean J Orthod 2015;45:13-9.

16. Thariq VK, Dilip S. Comparison of frictional resistance between interactive self ligating, passive self ligating and conventional orthodontic brackets - an in vitro study. IOSR J Dent Med Sci 2013;10:19-23.

17. Kumar A, Khanam A, Ghafoor H. Effects of intraoral aging of arch-wires on frictional forces: An ex vivo study. J Orthod Sci 2016;5:109-16.

18. Kim KS, Han SJ, Lee TH, Park TJ, Choi S, Kang YG, et al. Surface analysis of metal clips of ceramic self-ligating brackets. Korean J Orthod 2019;49:12-20. 